\title{
Relation of Body Mass Index with Lipid Profile and Blood Pressure in Healthy Females of Lower Socioeconomic Group, In Kosi Region, Bihar.
}

\author{
Arohi Abhinav Jayaswal \\ Department of Physiology \\ Katihar Medical College ,Katihar, Bihar
}

\begin{abstract}
Hypertension is an iceberg disease. It is the main risk factor for stroke and renal failure. Elevated levels of triglyceride, cholesterol and $L D L-C$ are documented as risk factors for atherogenesis. $L D L-C$ in its oxidized or acetylated form has been identified as a major atherogenic particle. Fifty four women between 2035 years of age attending Katihar medical college hospital OPD were used in this study. Their height, weight, systolic and diastolic blood pressures were recorded. Body Mass Index (BMI) was calculated by using their height (m2) and weight (kg). On the basis of BMI, all participants were divided into three groups that is under weight whose BMI was less than $19 \mathrm{~kg} / \mathrm{m} 2$, Normal who's BMI was between 19 and $26 \mathrm{~kg} / \mathrm{m} 2$ and overweight who's BMI was more than $26 \mathrm{~kg} / \mathrm{m} 2$. The mean BMI of the three groups in the 54 participants was $150.1 \mathrm{mg} / \mathrm{dl}$ \pm 31.7 , mean $L D L-C$ was $91.6 \mathrm{mg} / \mathrm{dl} \pm 22.6$, mean $H D L-C$ was $39.7 \mathrm{mg} / \mathrm{dl} \pm 9.1$ and mean triglycerides were 93.9 $\mathrm{mg} / \mathrm{dl} \pm 41$.6. Mean systolic blood pressure was $114.1 \mathrm{mmHg} \pm 11.8$ and mean diastolic blood pressure was 74.1 $m m H g \pm 7.9$. There were significant differences in mean serum $H D L-C$, triglycerides, systolic and diastolic blood pressure among three BMI groups $(P<0.05)$ but none in mean serum cholesterol and $L D L-C$. No significant correlation was found between any of the lipid profile variables and blood pressure variables with BMI. The importance of this finding is to enable "care-givers" in hypertension pay more attention to the control of obesity so that several complications associated with it might be prevented.
\end{abstract}

Key words: Hypertension, body mass index and cholesterol

\section{Introduction}

The association between hypertension and dyslipidemia is well established and both may add up to increase patient's susceptibility to the development of Coronary Heart Disease (CHD). Hypertension is more apt to cause Coronary Vascular Disease (CVD) in person with added risk factors such as elevated serum cholesterol People with Obesity and high blood pressure are also more likely to have lipid abnormality than those with normal blood pressure Wannarintheeet al. (1998). Furthermore blood pressure is strongly related to body weight and control of obesity is a critical component of prevention and control of hypertension Kummayinka (1997). Clinical trials have also suggested a reduction in the incidence of Ischemic heart disease by lowering serum cholesterol levels.

Hypertension is now a global epidemic affecting 1.5 billion people worldwide and claiming about 7 million lives every year. The prevalence of hypertension is probably on the increase in kosi region where adoption of western lifestyles and the stress of urbanization both of which are expected to increase the morbidity associated with unhealthy lifestyles are not on the decline. Genetic and environmental factors are reported to play a key role in IHD, $90 \%$ of which are better classified as idiopathic. Hypertension in adults has a high impact on the economy and on the quality of life of individuals with important implications for resource expenditures Jones et al. (1992).

Elevated levels of triglyceride, cholesterol and LDL-C are documented as risk factors for atherogenesis Lipid Research Clinic Program (1984). LDL-C in its oxidized or acetylated form has been identified as a major atherogenic particle; as it not only load macrophages with cholesterol for the formation of foam cells but also because it is chemotactic for circulating monocytes, is cytotoxic and can adversely alter coagulation pathways Fogelman et al. (1980). The blood level of HDL-C in contrast bears an inverse relationship of the risk of atherosclerosis and coronary heart disease that is higher the level, smaller the risk Witztumet al. (1991) and Palinskiet al. (1989)

Different plasma lipids vary significantly in various population groups due to difference in geographical, cultural Hartet al. (1997) economical, social conditions Vartiainen et al. (1997), dietary habits and genetic makeup. Age and gender differences also affect serum lipids considerably Malik et al. (1995) and Shahid et al.(1985). This study was conducted to assess serum lipids and blood pressure among non pregnant normotensive women belonging to a lower socioeconomic group, in Kosi region. 


\section{Materials And Methods}

Fifty four women between 20-35 years of age attending Katihar medical college hospital OPD were used in this study between March and August 2011. Their height, weight, systolic and diastolic blood pressures were recorded. Body Mass Index (BMI) was calculated by using their height $(\mathrm{m} 2)$ and weight $(\mathrm{kg})$. On the basis of BMI, all participants were divided into three groups that is under weight whose BMI was less than $19 \mathrm{~kg} /$ $\mathrm{m} 2$, normal who's BMI was between 19 and $26 \mathrm{~kg} / \mathrm{m} 2$ and overweight who's BMI was more than $26 \mathrm{~kg} / \mathrm{m} 2$. After twelve hours fast, serum samples were collected and total cholesterol, HDL-C, LDL-C and triglycerides were estimated on semiautoanalyzer microlab 300 supplied by Merk. Statistical analysis was done on Epi-Info6 . The means of the three groups were compared by ANOVA at the significance level of $s=0.05$.Correlation coefficient was determined for the dependent variables of lipid profile and blood pressure with BMI (in $\mathrm{kg} / \mathrm{m} \mathrm{2}$ ) as the independent variable.

\section{Result}

The height, weight, mean systolic and diastolic blood pressure and lipid profile levels were available for all the 54 women included in the study. The mean BMI of the three groups in the 54 participants was 150.1 $\mathrm{mg} / \mathrm{dl} \pm 31.7$, mean LDL-C was $91.6 \mathrm{mg} / \mathrm{dl} \pm 22.6$, mean HDL-C was $39.7 \mathrm{mg} / \mathrm{dl} \pm 9.1$ and mean triglycerides were $93.9 \mathrm{mg} / \mathrm{dl} \pm 41.6$. Mean systolic blood pressure was $114.1 \mathrm{mmHg} \pm 11.8$ and mean diastolic blood pressure was $74.1 \mathrm{mmHg} \pm 7.9$. Among 54 participants, 23 were underweight that is their BMI was less than $19 \mathrm{~kg} / \mathrm{m} 2$, 18 were normal that is their BMI was between $19 \mathrm{~kg} / \mathrm{m} 2$ and $26 \mathrm{~kg} / \mathrm{m} 2$ and 13 were overweight that is their BMI was more than $26 \mathrm{Kg} / \mathrm{m} 2$. Mean values of serum cholesterol, LDL-C, HDL-C, triglycerides, systolic and diastolic blood pressure with their standard deviations according to three BMI groups are given in Table 1 . There were significant differences in mean serum HDL-C, triglycerides, systolic and diastolic blood pressure among three BMI groups $(\mathrm{P}<0.05)$ but none in mean serum cholesterol and LDL-C. No significant correlation was found between any of the lipid profile variables and blood pressure variables with BMI. In this study, comparison of three BMI groups (underweight, normal and overweight) with regards to serum total cholesterol, LDL-C, HDL-C, triglycerides, mean systolic and diastolic blood pressure were also examined. Finding of this study shows there is positive and significant association between BMI and triglycerides which is similar to the findings of Donahueet al. (1985) and Prineaset al. (1980)., this study also found no significant difference (P > $0.05)$ in serum total cholesterol and LDL-C but there is significant difference $(p<0.05)$ in mean serum HDL-C, triglycerides, mean systolic and mean diastolic blood pressure in three BMI groups. The percentage of subjects who's BMI was > 30 in this study was $23 \%$ which is similar to the findings of Yekeenet al. (2003) who found $33 \%$. Ezenwakaet al. (1997) had also reported a higher prevalence of obesity and high blood pressure in women and in urban settings.

\section{Discussion}

It has been estimated that risk of hypertension is $35 \%$ to $55 \%$ less in adults of normal weight as compared to obese adults Manson et al. (1992). However, the influence of obesity on cardiovascular risk begins before adulthood and overweight during adolescence is associated with an increased risk of coronary heart disease in both male and female subjects Di Pietro et al. (1984). As $23.1 \%$ of our total study populations are overweight, so the number of at-risk individuals is not much higher. As the prevalence of hypertension in several population studies has overshot the $10 \%$ trigger- point, it is necessary to activate intervention to lower this rate. The control of dietary energy intake, sodium consumption and inactivity are areas of potential interventions. So far the prevalence of coronary heart disease is increasing in kosi region; paradoxically the risk factors of hypertension, obesity and high serum cholesterol associated with coronary heart disease are emerging.

\section{Conclusion}

The importance of this finding is to enable "caregivers" in hypertension pay more attention to the control of obesity so that several complications associated with it might be prevented. The risk factors of hypertension already seen in several of the obese patients can be lowered by dietary intervention, as well as other medical control of hypertension. It is clear that the population prevalence of obesity, hypertension and hyper-cholesterol if known will be useful in planning interventions. Therefore, strategies designed to limit cardiovascular risk should address weight reduction. 
Table 1 : Cholesterol, LDL-C, HDL-C, triglycerides, systolic blood pressure and diastolic blood pressure according to three BMI groups (Means \pm SD)

\begin{tabular}{|c|c|c|c|c|}
\hline Variables & $\begin{array}{l}\text { Underweight } \\
(\mathrm{BMI}<19 \mathrm{~kg} / \mathrm{m} 2)\end{array}$ & $\begin{array}{l}\text { Normal(BMI19- } \\
26 \mathrm{~kg} / \mathrm{m} \mathrm{2} \text { ) }\end{array}$ & $\begin{array}{l}\text { Overweight } \\
(\mathrm{BMI}>26 \mathrm{~kg} / \mathrm{m} 2)\end{array}$ & p-value* \\
\hline Cholesterol (mg/dl) & $144.2 \pm 31.4$ & $148.7 \pm 32.7$ & $154.5 \pm 32.3$ & 0.23 \\
\hline LDL-C (mg/dl) & $86.3 \pm 30.2$ & $91.2 \pm 23.6$ & $94.4 \pm 28.5$ & 0.26 \\
\hline HDL-C (mg/dl) & $42.9 \pm 8.3$ & $40.7 \pm 8.1$ & $38.7 \pm 5.9$ & 0.04 \\
\hline $\begin{array}{l}\text { Triglycerides } \\
(\mathrm{mg} / \mathrm{dl})\end{array}$ & $81.2 \pm 27.6$ & $90.2 \pm 40.6$ & $113.2 \pm 57.0$ & 0.001 \\
\hline $\mathrm{SBP}(\mathrm{mmHg})$ & $107.6 \pm 15.0$ & $112.6 \pm 12.8$ & $119.1 \pm 17.5$ & $<0.001$ \\
\hline $\mathrm{DBP}(\mathrm{mmHg})$ & $70.7 \pm 9.3$ & $73.5 \pm 8.9$ & $75.0 \pm 8.8$ & 0.01 \\
\hline
\end{tabular}

*p-value calculated by ANOVA comparing the means of the variables for the three BMI group

\section{References}

[1]. Daily Trust Tuesday, July 21, 2009. 22(17): 46http//www.dailytrustonline.com

[2]. Di Pietro, L., H.O. Mossberg and A.J. Stunkard, 1994. 40year history of overweight children in Stockholm: life-time overweight, morbidity, and mortality. Int.J.Obes., 18: 585-590.

[3]. Donahue, R.P., T.J. Orchard, L.H. Kuller and AL. Drash,1985. Lipids and lipoproteins in young adult population Am. J. Epidemiol., 240: 458-67.

[4]. Ezenwaka, C.E., A.O. Akanji, B.O. Akanji, N.C. Unwin, and C.A. Adejuwon, 1997. The prevalence of insulin resistance and other cardiovascular disease risk factors in healthy elderly south western Nigerians Artherosclerosis 128(2): 201-211.

[5]. Fogelman, A., I. Schechter and J. Seager, 1980.Alteration of low density lipoproteins leads to cholesterylester accumulation in human monocyte macrophages. Proc. Natl. Acad. Sci., USA,77:2214-2218.

[6]. Gordan H. Williams: Hypertensive vascular disease: Kasper Dennis L, Eugene Braunwald, Fauci AS, Hauser SL, Longo DL, Jameson JL, Harrison's Principle of Internal Medicine: 16th ed (2005): McGraw- New York : $1463-1487$ (s).

[7]. Hart, C., R. Ecob, and G.D. Smith, 1997. People, places and coronary heart disease risk factors: a multilevel analysis of the Scottish Heart Health Study archive. Soc. Sci. Med., 45: 893-902.

[8]. Jones, J. and K.A. Davis, 1992.Risk factors for coronary disease in a black population, J. Am. Med. Assoc., 84:393-398.

[9]. Kummayinka, S.K., 1997. The impact of obesity on hypertension management in African.Am. J.Healthcare Poor Underser., (3): 352-355.

[10]. Lipid Research Clinic Program, 1984. The lipid research clinic coronary primary prevention trial results II. J.Am. Med. Assoc., 251: 364-374.

[11]. Malik, R., Z.A. Pirzado, S. Ahmed and M. Sajid, 1995.Study of lipid profile, blood pressure and blood glucose in rural population. Pak. J. Med. Res., 34:152-155.

[12]. Manson, J.E., H. Tosteson, P.M. Ridker, S. Satterfield, P.Hebert, and G.T. O'Connor, et al. 1992. The primary prevention of myocardial infarction. N. Engl. J.Med., 326: 1406-1416.

[13]. Okosun, I.S., T.E. Forrester, C.N. Rotimi, B.O.Osotimehin, W.F. Muna and R.S. Cooper, 1999.abdominal adiposity in six populations of West African descents: prevalence and population

[14]. attributable fraction of hypertension. Obesity Res.,7 (5): 453-462.

[15]. Palinski, W., M. Rosenfeld and S. Yla-Herttuala, 1989.Low density lipoprotein undergoes oxidative modification in vivo., Proc. Natl. Acad. Sci., USA.86: 1372-1376.

[16]. Park K, Textbook of Preventive And Social Medicine, $20^{\text {th }}$ ed. (2009), Banarsidas Bhanot: p.323-324.

[17]. Prineas, R.J., R.F. Gillum, H. Horibe, and P.J. Hannan, 1980. The Minneapolis Children's Blood Pressure Study: standards of measurement for children's blood pressure. Hypertention, 2 (supplI): S18-24.

[18]. Shahid, A., S.J. Zuberi, and N. Hasnain, 1985.Lipid pattern in healthy subjects. Pak. J. Med. Res., 24:33-37.

[19]. Trimorthy CW, Peter OK, Charles J.G. Dyslipo- Proteinaemia in black participants. The lipid research Clinics program prevalence study. Circulation 1986; 73:1-119(s).

[20]. Vartiainen, E., J. Pekkanen, S. Koskinen, P. Jousilahti,V. Salomma and P. Puska, 1981. Do changes in cardiovascular risk factors explain the increasing socioeconomic difference in mortality From ischaemic heart disease in Finland? J. Epidemiol. Community. Health., 52: 416-419.

[21]. Wannarinthee, S.C., A.G. Shaper, P.N. Durington and M.Perry, 1998.Metabolic Syndrome.J. Human Hypertension, 12(2): 10591064 .

[22]. Witztum, J.L. and D. Steinberg, 1991.Role of oxidized low density lipoprotein in atherogenesis.J. Clin. Invest,88: 1785-1792

[23]. Yekeen, L.A., R.A. Sanusi and A.O. Ketiku, 2003.Prevalence of obesity and high level of cholesterol in hypertension: Analysis of Data from the University College Hospital, Ibadan. Afr. J. Biomed.Res., 6:129 -132. 